\title{
Simultaneous Quantification of Oleins (triolein, diolein and monoolein) in Mouse Feces using Liquid Chromatography-Electrospray Ionization/Mass Spectrometry
}

\author{
Jong Hyun Lim ${ }^{\mathrm{a}, \mathrm{c}}$, Jeongae Lee ${ }^{\mathrm{a}}$, Yura Jang ${ }^{\mathrm{b}}$, Hesson Chung ${ }^{\mathrm{b}}$, Won-Yong Lee ${ }^{\mathrm{c}}$, and Bong Chul Chunga,* \\ ${ }^{a}$ Molecular Recognition Research Center, Korea Institute of Science and Technology, Seoul 136-791, Korea \\ ${ }^{b}$ Brain Science Institute, Korea Institute of Science and Technology, Seoul 136-791, Korea \\ ${ }^{c}$ Department of Chemistry, Yonsei University, 50 Yonsei-ro, Seodaemun-gu, Seoul 120-749, Korea
}

Received August 27, 2012; Revised September 10, 2012; Accepted September 10, 2012

First published on the web September 20, 2012; DOI: 10.5478/MSL.2012.3.3.68

\begin{abstract}
Fat malabsorption is an important cause of poor growth in infancy and childhood. Steatorrhea tests have been developed using various methods. Traditional measurements of stool fat, however, require large samples and it often takes as a week to complete the analysis. In this paper, a liquid chromatography-electrospray ionization/mass spectrometry (LC-ESI/MS) method was developed for simultaneous quantitative analysis of triacylglycerols, triolein, diolein and monoolein, in mouse feces. Moreover, the procedure was rapid, simple as well as compatible with LC-ESI/MS. Chloroform-isopropyl alcohol solution was used for fat-soluble sample extraction. After centrifugation and filtration, an analytical solution was prepared. Triolein, diolein and monoolein were separated using non-aqueous reversed-phase column with the mobile phase consisting of A (methanol) and B (acetone-isopropyl alcohol). The precision ( $\% \mathrm{CV}$ ) and accuracy (\% bias) of the assay were 3.8-14.7\% and 85.2-114.9\%, respectively. This method has been successfully applied to simultaneous determination of triolein, diolein and monoolein in feces from 30 mice. This method can therefore be applied to measure triacylglycerols in mouse feces accurately and precisely by LC-ESI/ MS, thereby helping to predictive biomarker in fat malabsorption and diagnostic research.
\end{abstract}

Key words: Triacylglycerols, steatorrhea, LC-ESI/MS, Mouse feces

\section{Introduction}

Triacylglycerols (TGs) are essential fatty acids, and the major components of naturally occurring fats and oils from animal and vegetable sources consisting of $95-98 \%$ of the whole oil compositions. ${ }^{1}$ Structurally, TGs consist of three fatty acids esterified to a glycerol molecule. ${ }^{2}$ In human beings, TGs as source of energy are stored in fat tissues, and in thermal and mechanical protective layers surrounding important organs. They are playing an important part of human diet and their imbalances can lead to several human diseases, i.e. coronary heart disease, dyslipidaemia, obesity or inborn errors of metabolism. ${ }^{3}$ Malabsorption of fat is one of the most important gastrointestinal causes of malnutrition and growth retardation in childhood. Steatorrhea is the presence of excess fat in feces, and has a symptom of disorders of fat metabolism and malabsorption syndrome. The detection of steatorrhea is useful for the diagnosis of intestinal and pancreatic disease. ${ }^{4}$ Major methods to diagnose steatorrhea include van de Kalmer method, ${ }^{5}$ Sudan staining, ${ }^{6}$ Steatocrit test, ${ }^{7}$ and acid steatocrit test. ${ }^{8}$

\footnotetext{
*Reprint requests to Ph.D. Bong Chul Chung

E-mail: bcc0319@kist.re.kr
}

Van de Kalmer method requires large samples and often takes as long as a week to complete the analysis. ${ }^{5}$ Sudan staining is the use of Sudan dyes to stain Sudanophilic substances in the feces. Normally a stool sample of a healthy subject should show only a few drops of red-orange stained fat under the microscope. ${ }^{6}$ Steatocrit test or acid steatocrit test (separation of homogenate fecal by centrifugation) is a simple, rapid and semi-quantitative method to determine steatorrhea. $^{7,8}$

TGs have been separated using several chromatographic techniques such as gas chromatography (GC), super critical fluid chromatography and high-performance liquid chromatography (HPLC), and others. Analysis of TGs using GC requires a step to derivatize TGs due to its nonvolatile properties. HPLC methods are widely used in the analysis of TGs mixtures using silver ion normal-phase HPLC (AgHPLC) ${ }^{9,10}$ and non-aqueous reversed-phase HPLC (NARPHPLC) ${ }^{11-13}$ Ag-HPLC is very successful in the separation of lipids differing in the number and positions of double bonds as well as cis/trans isomerism. The retention of TGs in AG-HPLC increases as the number of double bonds increases, but the method has a low selectivity in the saturated part of the molecules. ${ }^{14-17}$ Separation by NARPHPLC is reserved for very hydrophobic samples that are retained strongly and not eluted by $100 \%$ acetonitrile $(\mathrm{ACN})$ 
as mobile phase. ${ }^{18}$ Several detectors are generally coupled with NARP-HPLC for TGs analysis. UV detection at low wavelengths (205 or $210 \mathrm{~nm}$ ) provide a linear response; however, a low sensitivity for saturated TGs has been reported. ${ }^{19,20}$ Evaporative light scattering is also employed, but is not appropriate for quantitative analyses due to the non-linear response. ${ }^{19}$ The refractive index detection cannot be applied with gradient elution ${ }^{21}$ although it is often used for routine quality control. Recently, mass spectrometry (MS) combined with atmospheric pressure chemical ionization (APCI) have been reported in the detection of TGs. ${ }^{3,22,23}$ However, when a mixture of TG was separated using RP-HPLC and identified using APCI-MS, the minimal fragmentation in APCI produced intense diacylglycerols ions ${ }^{24,25}$ and less information about molecular weight of the TGs is provided in general. During the interpretation of APCI mass spectra, the lack of intact protonated molecules produced from some oxygen functional group containing TGs is another shortcoming. ${ }^{26}$

The objective of this study was to develop a rapid, simple, and quantitative liquid chromatography-electrospray ioniza tion/mass spectrometry (LC-ESI/MS) method for simultaneous determination of oleins in steatorrhea. The current steatorrhea analysis is complex, time-consuming, nonquantitative, and therefore a new quantitative and accurate method is needed. We developed a method for the simultaneous determination of triolein, diolein, and monoolein in mouse feces using liquid chromatography-electrospray ionization/mass spectrometry (LC-ESI/MS) after oral administration of triolein. In the future, this analysis can become an accurate and routine method for early diagnosis of fat malabsorption disease.

\section{Experimental Section}

\section{Chemicals}

Reference standards of triolein, diolein, and monoolein were obtained from Sigma-Aldrich (St. Louis, MO, USA). $1,1,1-{ }^{13} \mathrm{C}_{3}$-Triolein as the internal standard (IS) was purchased from Cambridge Isotope Laboratories (Andover, MA, USA). Orlistat was a product of Biocon (Bangalore, India). Sudan IV was obtained from Sigma (St. Louis, MO, USA). All organic solvents, methanol, acetone and isopropyl alcohol were of analytical or HPLC grade and purchased from Burdick \& Jackson (Muskegon, MI, USA). Deionized water was prepared using a Milli-Q purification system (Millipore, Billerica, MA, USA).

\section{Standard solutions and quality-control samples}

The stock solutions of all the reference standards and IS were dissolved in ethanol at $1 \mathrm{mg} / \mathrm{mL}$, and the working solutions were made up with ethanol at concentrations of 1 , 10 , and $100 \mu \mathrm{g} / \mathrm{mL}$. The IS working solution at $10 \mu \mathrm{g} / \mathrm{mL}$ was prepared by diluting the IS stock solution. All standard solutions were stored at $-20{ }^{\circ} \mathrm{C}$ until required. The qualitycontrol (QC) samples were prepared using olein-free fecal extract spiked with oleins at three different concentrations $(1,5$, and $20 \mu \mathrm{g} / \mathrm{mL})$.

\section{LC-MS conditions}

LC-ESI/MS analysis was performed using Shiseido Nanospace SI-2 high performance liquid chromatograph (Tokyo, Japan) interfaced with an ion-trap ThermoFinnigan LCQ Advantage mass spectrometry (San Jose, CA, USA). All oleins were separated using a Sunfire $C_{8}(150 \mathrm{~mm}$ length $\times 2.1 \mathrm{~mm}$ i.d., $3.5 \mu \mathrm{m}$ particle size; Waters, Milford, MA, USA) at $150 \mu \mathrm{L} / \mathrm{min}$. After injection, the mobile phase consisting of A (methanol) and B (acetone-isopropyl alcohol $(1: 1, \mathrm{v} / \mathrm{v}))$ was controlled as follows: $0 \mathrm{~min}$ at $1 \%$ B; 0-7 min, $1-50 \% \mathrm{~B} ; 7.1-17 \mathrm{~min}, 50-60 \% \mathrm{~B} ; 17.1-19 \mathrm{~min}$, $60-95 \% \mathrm{~B} ; 19-20 \mathrm{~min}, 95-1 \% \mathrm{~B}$. The gradient was then returned to the initial condition $(1 \% \mathrm{~B})$ and held for $10 \mathrm{~min}$ before the next sample was run. All oleins were detected in positive ionization with their $[\mathrm{M}+\mathrm{Na}]^{+}$ion as the precursor ion (Table 1). The mass spectrometry was operated under the following optimized conditions: ion spray voltage, $5.5 \mathrm{kV}$; capillary voltage, $18 \mathrm{~V}$; tube lens offset, $30 \mathrm{~V}$; capillary temperature, $280{ }^{\circ} \mathrm{C}$; multiplier voltage, $400 \mathrm{~V}$. Nitrogen was used as the sheath gas at 20 arbitrary units. Mass spectra were acquired in the range of $\mathrm{m} / \mathrm{z} 50-1200$.

\section{Sample preparation}

Female BALB/c (7 weeks) mice were obtained from NARA biotech Co. Ltd (Seoul, Korea). They were housed under a $12 \mathrm{~h}$ light/dark cycle in a cage and given food and water ad libitum. Care and handling followed institutional guidelines of the Animal Care and Use Committee in Korea Institute of Science and Technology. Triolein containing Sudan IV at volumes of 10 to $100 \mu \mathrm{L}$ (Sudan IV of $2 \mathrm{mg}$ / $\mathrm{mL}$ in triolein), three mice per each dose group, were

Table 1. The LC-ESI/MS information of oleins analyzed

\begin{tabular}{ccccccc}
\hline \hline Compound & TG type & Molecular weight & Precursor ion $(\mathrm{m} / \mathrm{z})$ & Product ion $(\mathrm{m} / \mathrm{z})$ & $\mathrm{CE}(\%)$ & $\mathrm{RT}(\mathrm{min})$ \\
\hline Triolein & $\mathrm{C} 18: 1 / \mathrm{C} 18: 1 / \mathrm{C} 18: 1$ & 885.4 & $907.8[\mathrm{M}+\mathrm{Na}]^{+}$ & 625.3 & 42 & 11.93 \\
Diolein & $\mathrm{C} 18: 1 / \mathrm{C} 18: 1$ & 620.9 & $643.5[\mathrm{M}+\mathrm{Na}]^{+}$ & 361.1 & 42 & 5.23 \\
Monoolein & $\mathrm{C} 18: 1$ & 356.5 & $379.1[\mathrm{M}+\mathrm{Na}]^{+}$ & - & - & 3.01 \\
${ }^{13} \mathrm{C}_{3}$-triolein & $\mathrm{C} 18: 1 / \mathrm{C} 18: 1 / \mathrm{C} 18: 1$ & 888.3 & $910.7[\mathrm{M}+\mathrm{Na}]^{+}$ & 628.2 & 42 & 11.92 \\
\hline
\end{tabular}

$\mathrm{CE}$; Collision energy, RT ; Retention time 
administered to mice orally, and feces and oil-stained fur were collected after $15 \mathrm{~h}$. Oil in the feces and fur were extracted with organic solvent mixture (chloroform : isopropyl alcohol $=1: 19$ by volume) by adding $5 \mathrm{~mL}$ of the solvent to 1 gram of the feces or fur by homogenizing them. These samples were centrifuged at $10,000 \mathrm{rpm}$ for $10 \mathrm{~min}$ at $4{ }^{\circ} \mathrm{C}$, and then all supernatants were kept at $-20{ }^{\circ} \mathrm{C}$ until use. To $200 \mu \mathrm{L}$ of supernatant, $25 \mu \mathrm{L}$ of internal standard (IS) solution containing $1,1,1-{ }^{13} \mathrm{C}_{3}$-triolein $(10 \mu \mathrm{g} / \mathrm{mL})$ was added. The mixture was vortexed for $30 \mathrm{~s}$ and then filtrated using polyvinylidene fluoride (PVDF) membrane syringe filter $(0.2 \mu \mathrm{m}$ pore size; Millipore). Three microliters of the

\section{(1)}
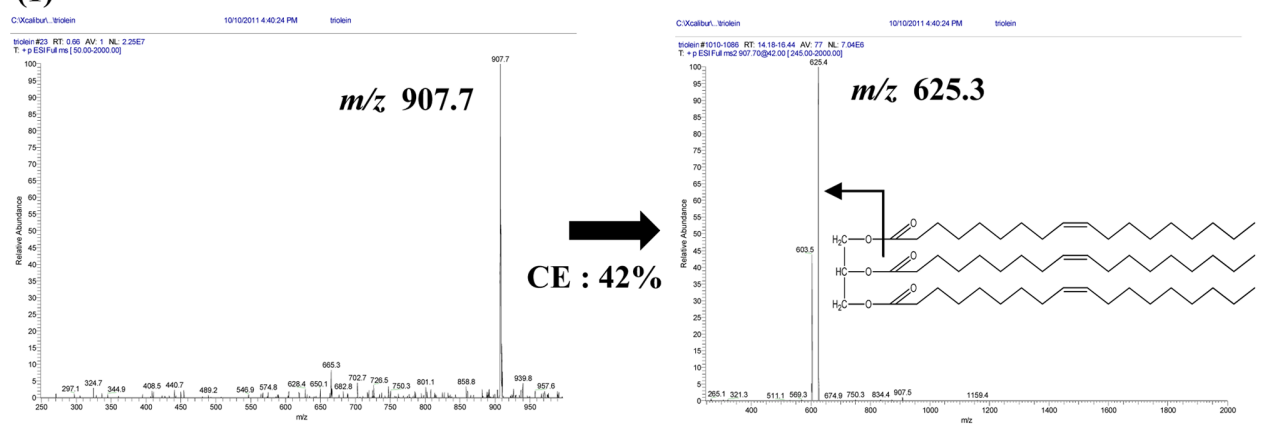

(2)
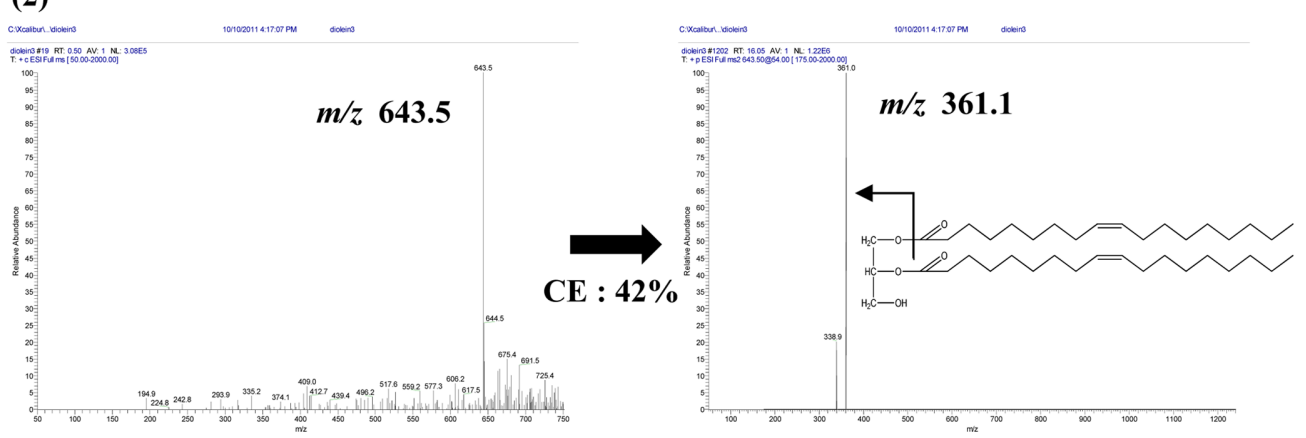

(3)

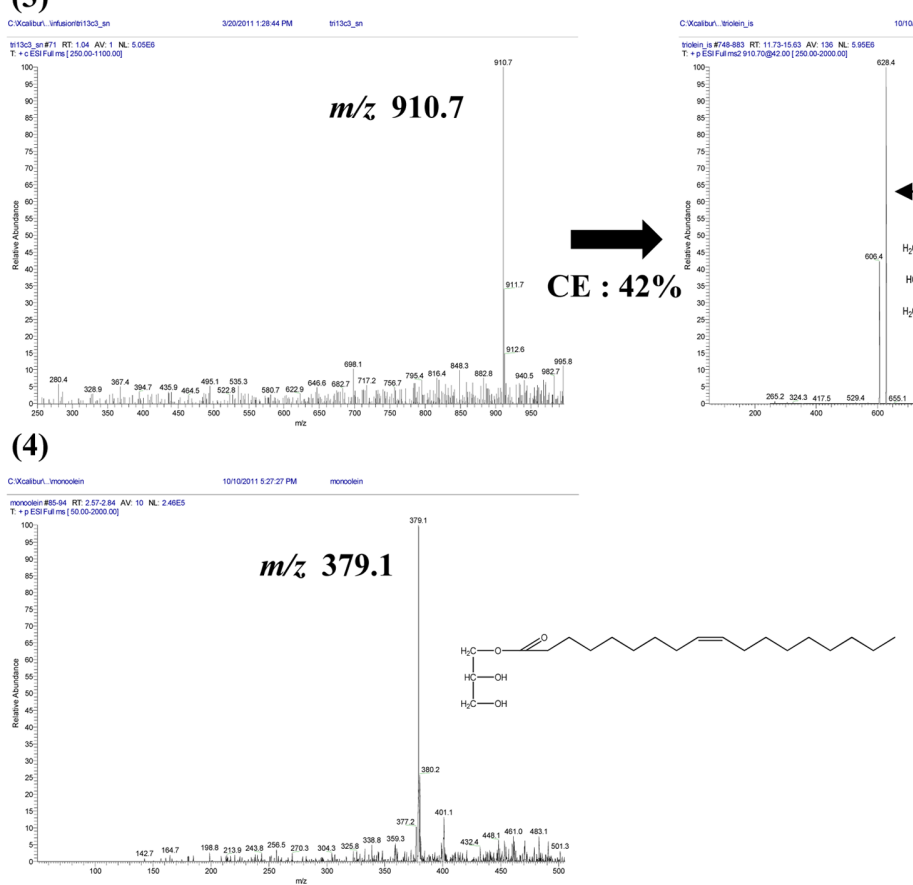

Figure 1. The LC-ESI/MS mass spectrums in the full scan mode and SRM mode of the oleins (1) triolein, (2) diolein, (3) ${ }^{13} \mathrm{C}_{3}$-triolein as an internal standard, and (4) monoolein. 
filtrate was subjected to LC-ESI/MS analysis.

\section{Method validation}

The QC samples containing the oleins were quantified using the peak area ratios of each olein versus the corresponding IS. Calibration samples were made up at twelve different concentrations, which depended on the sensitivity. The limits of detection (LOD) and quantification (LOQ) were defined as the lowest concentration with a signal-to-noise $(\mathrm{S} / \mathrm{N})$ ratio $>3$ and 10 , respectively. Three samples at three different concentrations (1, 5, and $20 \mu \mathrm{g}$ / $\mathrm{mL}$ ) were analyzed. Precision and accuracy were expressed as the coefficients of variation $(\% \mathrm{CV})$ and the percentage relative errors ( $\%$ bias), respectively. The intra- and interday assays were determined by the analysis of five replicates and the running of the samples on five different days. The extraction recoveries were determined using the QC samples at three different concentrations by adding known amounts of analytes to the olein-free samples.

\section{Thin layer chromatography}

Thin layer chromatography (TLC) experiments were performed on $5 \times 10 \mathrm{~cm}$ aluminum-backed precoated silica gel HPTLC 60 Merck-5556-4 plates (Merck, Whitehouse Station, NJ, USA). The mobile phase was methyl alcohol: chloroform $=1: 4$ by volume. Sudan IV, a red dye, was visualized by naked eye. TLC plate was scanned by a laser scanner for image analysis. After scanning, the plate was immersed in $10 \%$ sulfuric acid solution briefly. TLC plate was heated to about $250{ }^{\circ} \mathrm{C}$ for about 10 minutes on a hot plate to reveal charred black carbon for sample detection. The plate was scanned once again for image processing of blackened spots. Each spot on the scanned images was processed by using Photoshop software. The area and average intensity was evaluated to calculate the intensity (= area $\mathrm{x}$ average intensity) for each spot.

\section{Results and Discussion}

\section{Optimization of the LC-ESI/MS conditions}

The mass spectra of the analytes and IS demonstrated a sodium adducted ions $[\mathrm{M}+\mathrm{Na}]^{+}$at $\mathrm{m} / z$ 907.8 for triolein, $\mathrm{m} / z 643.5$ for diolein, $\mathrm{m} / \mathrm{z} 379.1$ for monoolein, and $\mathrm{m} / \mathrm{z}$ 910.7 for IS. ${ }^{13} \mathrm{C}_{3}$-Triolein was selected as the IS because it could give satisfactory retention time and extraction efficiency, which were similar to those of triolein. In the selected-reaction monitoring (SRM) mass spectra, when collision energy (CE) was $42 \%$, the ion peak at $\mathrm{m} / \mathrm{z} 625.3$ for triolein, $m / z 361.1$ for diolein and $m / z 628.2$ for IS, corresponding subsequently to the loss of oleic acid. Fragmentation pattern of triolein, diolein and IS were shown in Figure 1. However, the determination of monoolein was performed by using Selected-ion monitoring (SIM) mode since the molecule contains one oleic acid. When CE was applied in the analysis of monoolein, product ion at $\mathrm{m} / \mathrm{z} 97$ was too low abundant interfered with background signal.

Separation of TGs required non-aqueous reversed-phase chromatography (NARP), because hydrophobic samples are strongly retained in RP column and are not eluted by $100 \%$ ACN as the mobile phase. ${ }^{27,28}$ The mobile phase for NARP separations will therefore consist of a mixture of more polar (A-solvent) and less polar (B-solvent) organic solvents. Often the A-solvent can be $\mathrm{ACN}$ or $\mathrm{MeOH}$, while the B-solvent can be acetone, chloroform, iso-propyl alcohol, methylene chloride, or other less polar organic solvents. Sample retention is controlled by the gradient mode by varying the percentage and/or the polarity of the B-solvent. Both $\mathrm{C} 8$ and $\mathrm{C} 18$ columns are considered as examples of reversed phase liquid chromatography (RP). The difference between the two columns will be in the length of the carbonchain attached to the silica surface. Both are reversed phase, but $\mathrm{C} 18$ columns will be more hydrophobic rather than the C8 columns. So, we used C8 column as a less hydrophobic column with symmetric peak shape and optimized RT. Under the LC conditions used, chromatographic resolution was improved oleins were separated within $30 \mathrm{~min}$ in olein standards (triolein, diolein, monoolein and ${ }^{13} \mathrm{C}_{3}$-triolein) and mouse feces sample (Figure 2).

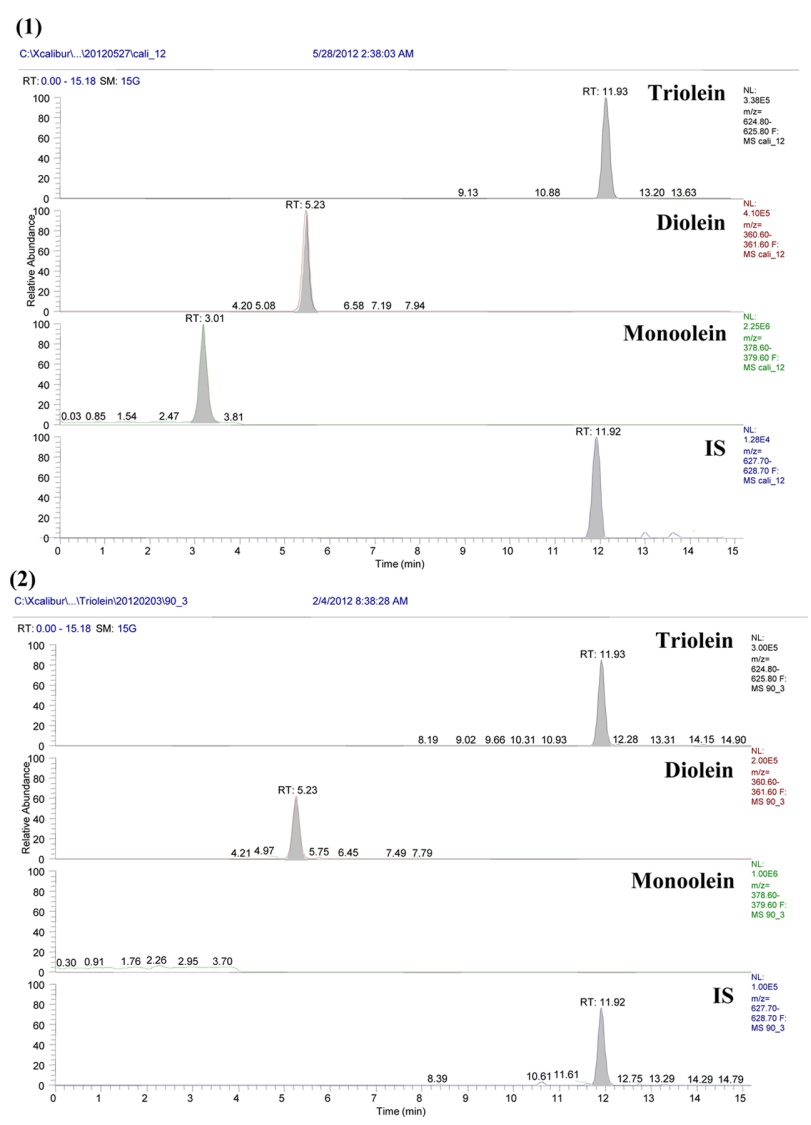

Figure 2. Extracted ion chromatograms of (1) olein standards and (2) mouse feces sample. 
Table 2. Validation results of intra- and inter-day assays for the oleins

\begin{tabular}{|c|c|c|c|c|c|c|c|}
\hline \multirow[b]{2}{*}{ Compound } & \multirow[b]{2}{*}{ Conc. } & \multicolumn{2}{|c|}{ Intra-day $(\mathrm{n}=5)$} & \multicolumn{2}{|c|}{ Inter-day $(\mathrm{n}=5)$} & \multirow[b]{2}{*}{ LOD } & \multirow[b]{2}{*}{ LOQ } \\
\hline & & Precision & Accuracy & Precision & Accuracy & & \\
\hline & $(\mu \mathrm{g} / \mathrm{mL})$ & $(\% \mathrm{CV})$ & (\% bias) & $(\% \mathrm{CV})$ & (\% bias) & $(\mu \mathrm{g} / \mathrm{mL})$ & $(\mu \mathrm{g} / \mathrm{mL})$ \\
\hline \multirow[t]{3}{*}{ Triolein } & 1.0 & 9.6 & 106.3 & 8.5 & 90.8 & & \\
\hline & 5.0 & 8.0 & 97.9 & 11.9 & 104.2 & 0.3 & 1.0 \\
\hline & 20.0 & 3.8 & 99.7 & 5.3 & 104.2 & & \\
\hline \multirow[t]{3}{*}{ Diolein } & 1.0 & 13.9 & 110.7 & 13.4 & 90.9 & & \\
\hline & 5.0 & 10.6 & 85.2 & 9.8 & 103.3 & 0.3 & 1.0 \\
\hline & 20.0 & 5.5 & 94.6 & 8.7 & 93.2 & & \\
\hline \multirow[t]{3}{*}{ Monoolein } & 1.0 & 12.8 & 114.9 & 14.3 & 102.4 & & \\
\hline & 5.0 & 14.7 & 95.6 & 7.2 & 100.7 & 0.3 & 1.0 \\
\hline & 20.0 & 5.6 & 99.9 & 10.6 & 95.1 & & \\
\hline
\end{tabular}

LOD, limit of detection; LOQ, limit of quantification; $\mathrm{CV}$, coefficient of variation

\section{Method validation}

Method validation required an LOD, an LOQ, linearity, recovery, precision, and accuracy using QC samples. A calibration curve was generated for all analytes using the QC samples fortified with all reference standards at three different concentrations $(1,5$ and $20 \mathrm{ig} / \mathrm{mL})$ for the three oleins. Quantification was based on peak area ratios versus the IS. Calibration samples were prepared at twelve different concentrations (each containing triolein, diolein and monoolein). Least-squares regression analysis was performed on peak area ratios obtained at different concentrations to obtain the calibration curves. The assay method was found to be linear and all the validation parameters were within acceptance range. Triolein, diolein and monoolein had an LOQ of $1.0 \mu \mathrm{g} / \mathrm{mL}$. The devised method was found to be linear $\left(\mathrm{R}^{2}=0.994-0.999\right)$ over the dynamic ranges (LOQ-50 $\mu \mathrm{g} / \mathrm{mL}$ each; Table 2). Precision and accuracies were determined by the analysis of the prepared QC samples. The intra-day $(\mathrm{n}=5)$ precision $(\%$ $\mathrm{CV}$ ) was $3.8-14.7 \%$, while the accuracy (\% bias) was $85.2-$ $114.9 \%$. The inter-day $(\mathrm{n}=5)$ precision and accuracy was $5.3-14.3 \%$ and $90.8-104.2 \%$, respectively.

\section{Quantification of oleins in mouse feces}

Fat in the mouse feces and fur were extracted and

Table 3. Result of triolein, diolein and monoolein (mean \pm SD)

\begin{tabular}{ccccc}
\hline \hline $\begin{array}{c}\text { Oral dose } \\
(\mu \mathrm{L})\end{array}$ & $\begin{array}{c}\text { Feces weight } \\
(\mathrm{g})\end{array}$ & $\begin{array}{c}\text { Triolein } \\
(\mathrm{mg})\end{array}$ & $\begin{array}{c}\text { Diolein } \\
(\mathrm{mg})\end{array}$ & $\begin{array}{c}\text { Monoolein } \\
(\mathrm{mg})\end{array}$ \\
\hline 10 & $0.50 \pm 0.04$ & $4.35 \pm 1.81$ & $1.82 \pm 0.52$ & N.D. \\
30 & $0.50 \pm 0.11$ & $9.82 \pm 4.35$ & $7.26 \pm 2.22$ & N.D. \\
50 & $0.47 \pm 0.11$ & $9.13 \pm 1.64$ & $4.95 \pm 0.78$ & N.D. \\
70 & $0.54 \pm 0.22$ & $4.44 \pm 1.34$ & $10.90 \pm 3.48$ & N.D. \\
90 & $0.50 \pm 0.09$ & $17.50 \pm 8.92$ & $14.97 \pm 3.72$ & N.D. \\
\hline
\end{tabular}

SD, standard deviation; N.D., not detection homogenized as above. We determined the concentrations of oleins (trioein, diolein and monoolein) in mouse feces extract by LC-ESI/MS method. The concentrations of

(1)

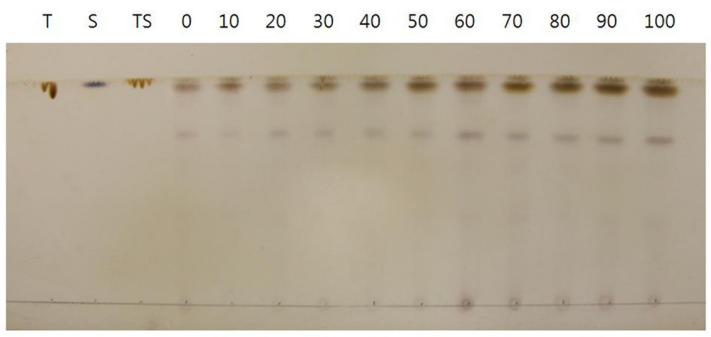

(2)

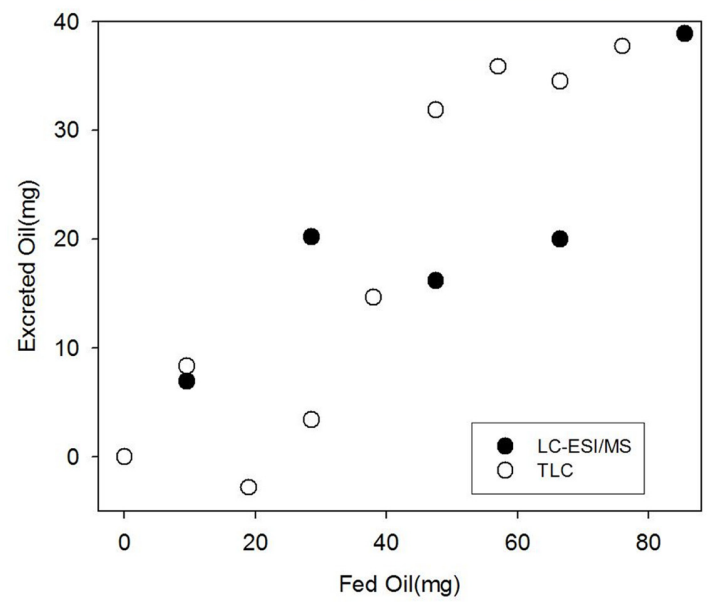

Figure 3. Thin layer chromatography of extracts of mouse feces and fur fed with from 0 to $90 \mu \mathrm{L}$ of triolein solution containing Sudan IV at $2 \mathrm{mg} / \mathrm{mL}$ (1). T: triolein, S: Sudan IV and TS: Sudan IV dissolved in triolein at $2 \mathrm{mg} / \mathrm{mL}$ were used as controls. Quantification of excreted oils from mice fed with 0 to $90 \mu \mathrm{L}$ of triolein by LC-ESI/MS (solid circles) and TLC (open circles) (2). For LC-ESI/MS, the mass of excreted diolein was converted and added to the corresponding triolen to calculate total excreted oil. 
triolein and diolein increased as the administrated dose increased. Monoolein was not detected in the feces and fur probably because orlistat was co-administrated to prevent lipid digestion in the intestine. Portion of triolein was degraded to diolein by lipase, monoolein, however, may not have been formed or could have been absorbed to the system to be detected in the fecal matter (Table 3).

\section{Quantification of excreted oils by thin layer chromatog- raphy}

The extracts obtained from feces and fur after feeding 0 to $90 \mu \mathrm{L}$ of triolein containing Sudan IV at $2 \mathrm{mg} / \mathrm{mL}$ were spotted on a TLC plate and developed to reveal oil spots (Figure 3). Triolein, Sudan IV and triolein/Sudan IV were used as controls. Sudan IV had red color that can be identified by naked eye. After burning the plate, Sudan IV was charred to black spots at $\mathrm{Rf}=1$. A little below the spots from Sudan IV, spots from triolein were revealed at $\mathrm{Rf}=0.95$. Diolen and other oils were spotted at $\mathrm{Rf}=0.72$. The Spots from trioleins were quantified by image analysis and plotted in Figure 3 (1). The excreted oils from the mice quantified by TLC (open circles) coincide well with those quantified by LC-ESI/MS (solid circles) in Figure 3 (2).

\section{Conclusions}

In this paper, a LC-MS method was developed for simultaneous quantitative analysis of triacylglycerols (TGs) in mouse feces using liquid chromatography-electrospray ionization/mass spectrometry. Our sample preparation procedure was rapid, simple than traditional measurements of stool fat. Moreover, separation of TGs was optimized with well-defined peak shapes and RTs by using a less hydrophobic $\mathrm{C} 8$ column than $\mathrm{C} 18$ reverse-phase column. This method has been successfully applied to simultaneous determination of triolein, diolein and monoolein in feces from 30 mice. The concentrations of triolein and diolein increased linearly as the administrated dose increased. However, monoolein was not detected in the samples because orlistat, a lipase inhibitor, was co-administrated with triolein. This method can therefore be applied to measure TGs in mouse feces accurately and precisely by LC-ESI/MS, thereby helping to predictive biomarker in fat malabsorption such as steatorrhea, intestinal and pancreatic disease and for the diagnostic research.

\section{Acknowledgement}

This study was supported by an intramural grant from the Korea Institute of Science and Technology (KIST) and by the Converging Research Center Program through the Ministry of Education, Science and Technology (2011K000885).

\section{References}

1. Lerma-García, M. J.; Lusardi, R.; Chiavaro, E.; Cerretani, L.; Bendini, A.; Ramis-Ramos, G.; Simó-Alfonso, E. F. J. Chromatogr. A 2011, 1218, 7521.

2. Cai, S.-S.; Short, L. C.; Syage, J. A.; Potvin, M.; Curtis, J. M. J. Chromatogr. A 2007, 1173, 88.

3. Lisa, M.; Holcapek, M. J. Chromatogr. A 2008, 1198, 115.

4. Van den Neucker, A.; Pestel, N.; Tran, T. M.; Forget, P. P.; Veeze, H. J.; Bouquet, J.; Sinaasappel, M. Acta Paediatr. 1997, 86, 466.

5. Van de Kalmer, J. H.; Ten Bokkel Huinin, K. H.; Wayers, H. A. J. Biol. Chem. 1949, 177, 347.

6. Drummy, G. D.; Benson, J. A.; Jone, C. M. N. Engl. J. Med. 1961, 264, 85.

7. Phuaradit, P.; Narang, A.; Mendonca, P.; Harris, D. A.; Baum, J. B. Arch. Dis. Child. 1981, 56, 725.

8. Tran, T. M.; Forget, P.; Van den Neucker, A.; van Kreel, B.; Kuijten, R. J. Pediatr. Gasroenterol. Nutr. 1994, 19, 299.

9. Dobson, G.; Christie, W. W.; Nikolova-Damyanova, B. J. Chromatogr. B 1995, 671, 197.

10. Mangos, T. J.; Jones, K. C.; Foglia, T. A. Chromatographia 1999, 49, 363.

11. Laakso, P. Food Rev. Int. 1996, 12, 199.

12. Lipp, M. Food Chemistry 1995, 54, 213.

13. Christie, W. W. Analusis 1998, 26, M34.

14. Christie, W. W. J. Chromatogr. 1988, 454, 273.

15. Schuyl, P. J. W.; de Joode, T.; Vasconcellos, M. A.; Duchateau, G. S. M. J. E. J. Chromatogr. A 1998, 810, 53.

16. Laakso, P.; Voutilainen, P. Lipids 1996, 31, 1311.

17. Adlof, R.O.; Menzel, A.; Dorovska-Taran, V. J. Chromatogr. A 2002, 953, 293.

18. Campbell, M. K.; Farrell, S. O. Biochemistry, 5th ed., Thomson brooks/cole; CA 94002 USA, 2006.

19. Holèapek, M.; Lísa, M.; Jandera,P.; Kabatova, N. J. Sep. Sci. 2005, 28, 1315.

20. Holèapek, M.; Jandera, P.; Fischer, J. Crit. Rev. Anal. Chem. 2001, 31, 53.

21. Jham, G. N.; Nikolova-Damyavova, B.; Viera, M.; Natalino, R.; Rodriques, A. C. Phytochem. Anal. 2003, 14, 310.

22. Nagy, K.; Bongiorno, D.; Avellone, G.; Agozzino, P.; Ceraulo, L.; Vékey, K. J. Chromatogr. A 2005, 1078, 90.

23. Lísa, M.; Holèapek, M.; Bohác, M. J. Agric. Food Chem. 2009, 57, 6888.

24. Byrdwell, W. C.;-Neff, W. E. J. Chromatogr. A 1999, $852,417$.

25. Byrdwell, W. C.; Emken, E. A. Lipids 1995, 30, 173.

26. Byrdwell, W. C., Neff, W. E. Rapid Commun. Mass Spectrom. 2002, 16, 300.

27. Craft , N. E.; Wise, S. A.; Soares, J. H. J. Chromatogr. 1992, 589, 171

28. Philipsen, H. J .A., J. Chromatogr. A 2004, 1037, 329. 